http://jmscr.igmpublication.org/home/ ISSN (e)-2347-176x ISSN (p) 2455-0450

crossref DOI: https://dx.doi.org/10.18535/jmscr/v7i12.24

\author{
(D) Journal Of Medical Science And Clinical Research \\ IGM Publication \\ An official Publication of IGM Publication
}

$\underline{\text { Research Article }}$

\title{
A Clinical Study on Ectopic Pregnancy
}

\author{
Authors \\ Prem Singh Tak*, Kalpana Mehta, Vimla Choudhary \\ Department of Obstetrics and Gynecology, Dr S N Medical College, Jodhpur, Rajasthan \\ *Corresponding Author \\ Prem Singh Tak
}

Dr S N Medical College, Jodhpur, Rajasthan

\begin{abstract}
Background: Ectopic pregnancy is defined as any intra or extra uterine pregnancy in which the fertilized ovum implants at an aberrant site which is unfavorable to its growth and development. It is the most important cause of maternal mortality and morbidity in the first trimester. It occurs when the developing blastocyst implants either outside the uterus or in an abnormal position within the uterus corneal.

Objective: To find out the incidence of ectopic pregnancy and to determine the clinical features, risk factors, treatment and assessment of risk of maternal mortality and morbidity in a tertiary care hospital.

Material and Methods: This was a retrospective observational study conducted over a period of two years. A total of 17560 deliveries occur during this period and 78 cases were diagnosed as ectopic pregnancy. Data were collected from labor ward and operation theatre registers. All these cases were analyzed with respect to the history, clinical presentation, investigations and treatment.

Results: Out of 17560 deliveries 78 cases were diagnosed as ectopic pregnancy giving the incidence of $0.44 \%$. A majority of the patients $(70.51 \%$ ) belonged to the age group of $20-30$ yrs. Among that $71.8 \%$ were multigravida and $28.2 \%$ were primi gravid. Cervical motion tenderness was found to be a significant finding in $64(82.05 \%)$ cases followed by adenaxal mass in 61 (78.20\%) cases. The commonest site for ectopic pregnancy was tubal (93.58\%) followed by ovarian (3.84\%). Ruptured ectopic was present in $79.48 \%$ cases on laparotomy while $11.53 \%$ were unruptured.
\end{abstract}

Conclusion: Ectopic pregnancy is a leading cause in young reproductive woman. High degree of suspicion and early diagnosis is the key to successful management.

Keywords: Amenorrhea, Ectopic pregnancy, Maternal mortality, Ruptured ectopic, Tubectomy.

\section{Introduction}

Ectopic pregnancy is the most important cause of maternal mortality and morbidity in the first trimester $^{1}$. It occurs when a fertilized ovum implants outside the normal uterine cavity or when the developing blastocyst implants either outside the uterus [Fallopian tube: ampullary (79.6\%); isthmic (12.3\%); fimbrial (6.2\%), Ovary
$(0.15 \%)$ and abdominal cavity $(1.4 \%)]$ or in an abnormal position within the uterus cornual $(1.9 \%)$, cervical $(0.15 \%)^{2}$. The most common type of ectopic pregnancy is tubal pregnancy. Approximately $98.3 \%$ of ectopic pregnancies occur in the fallopian tubes.

Risk factors like previous ectopic pregnancy, tubal corrective surgery, tubal sterilization, intrauterine 
devices, documented tubal pathology, infertility, assisted reproductive techniques, PID, smoking, prior abortions, multiple sexual partners and prior delivery have been implicated in the development of the ectopic pregnancy ${ }^{3}$.

The rate of ectopic pregnancy in most of the hospital is $1-2 \%^{4-6}$. Patients with an ectopic pregnancy commonly present with pain and vaginal bleeding between 6 and 10 weeks of gestation $^{7}$.The diagnosis of ectopic pregnancy is complicated by wide spectrum of clinical presentations, from asymptomatic cases to acute abdomen, and hemodynamic shock $^{8}$. Early diagnosis reduces the risk of tubal rupture and allows more conservative medical treatments to be employed ${ }^{9}$.

The current trend is a conservative way of management of these pregnancies be it chemotherapeutic agents or conservative surgical approaches, the ultimate goal is tubal conservative procedures rather than radical surgeries ${ }^{10,11}$. The availability of sensitive hcg and high-resolution sonography has resulted in earlier diagnosis and has reduced mortality rate ${ }^{12}$. This retrospective study was done to determine the incidence, clinical features, risk factors, treatment and morbidity and mortality associated with ectopic pregnancy in a tertiary care hospital.

\section{Material and Methods}

Study Population: This was a retrospective observational study conducted in the Department of Obstetrics and Gynecology, Mathura Das Mathur Hospital under Dr S N Medical College, Jodhpur, Rajasthan over a period of two years from January 2017 to December 2018. There were 17560 deliveries during this period and 78 cases were diagnosed as ectopic pregnancy. The women who were diagnosed as ectopic pregnancy cases, who were in the reproductive age group of 15 to 44 years were included. All intrauterine pregnancies and ectopic pregnancies managed by medical or expectant management were excluded. The study was approved by the Institute Ethics Committee.

\section{Methodology}

The case sheets of the patients with ectopic pregnancy were traced through the labor ward registers and operation theatre registers. Information regarding the total number of ectopic pregnancies in the study period, details of demographic characteristics, clinical symptoms and signs, diagnostic tools used, treatment, risk factors for the ectopic pregnancy as well as associated morbidity and mortality were obtained. Statistical analysis was done by using SPSS software version 21.

\section{Results}

Out of 17560 deliveries 78 cases were diagnosed as ectopic pregnancy giving the incidence of $0.44 \%$. A majority of the patients $(70.51 \%)$ belonged to the age group of 20-30 yrs (Table 1). In the present study, $71.8 \%$ were multigravida and $28.2 \%$ were primi gravid. (Table 2) Out of 78 cases of ectopic pregnancy all the patients i.e $100 \%$ have abdominal pain followed by $93.58 \%$ had amenorrhoea and $69.23 \%$ had bleeding problem. (Table 3)

Out of 78 patients cervical motion tenderness was found to be a significant finding in $64(82.05 \%)$ cases followed by adenaxal mass in $61(78.20 \%)$ cases. Other symptoms like pallor, abdominal lump was seen $73.07 \%$ and $39.74 \%$ respectively. (Table 4)

The urinary pregnancy test was positive in $96.15 \%$ of the cases while $3.85 \%$ were negative. (Table 5)

Of the total 78 cases of ectopic pregnancies, there was no specific risk factor in 43 cases $(55.12 \%)$, PID in 13 cases (16.6\%) followed by D and $\mathrm{C}$ in 9 cases $(11.54 \%)$, IUCD in 7 cases $(8.97 \%)$, tubectomy in 5 cases $(6.41 \%)$ and previous ectopic in one case $(1.28 \%)$. (Table 6)

The commonest site for ectopic pregnancy was tubal $(93.58 \%)$ followed by ovarian $(3.84 \%)$ and cornual and C/S Scar both (1.28\%). (Table 7) In this study ruptured ectopic was present in $79.48 \%$ cases on laparotomy while $11.53 \%$ were 
unruptured ectopic cases and tubal abortion was found in $8.97 \%$ cases. (Table 8 )

Table 1 Age of study population

\begin{tabular}{|l|c|c|}
\hline Age & Number & Percentage \\
\hline$<20$ years & 12 & $15.4 \%$ \\
\hline 20-25 years & 34 & $43.6 \%$ \\
\hline 26-30 years & 21 & $26.9 \%$ \\
\hline$>30$ years & 11 & $14.1 \%$ \\
\hline
\end{tabular}

Table 2 Incidence of Ectopic Pregnancy According to the Gravidity

\begin{tabular}{|l|c|c|}
\hline Gravidity & Frequency & Percentage \\
\hline Primi & 22 & $28.2 \%$ \\
\hline Multi & 56 & $71.8 \%$ \\
\hline
\end{tabular}

Table 3 Distribution of various symptoms in Ectopic Pregnancy

\begin{tabular}{|l|c|c|}
\hline Symptoms & Frequency & Percentage \\
\hline Amenorrhea & 73 & $93.58 \%$ \\
\hline Pain abdomen & 78 & $100 \%$ \\
\hline Bleeding & 54 & $69.23 \%$ \\
\hline Others Associated & 22 & 28.20 \\
\hline
\end{tabular}

Table 4 Different signs in Ectopic Pregnancy

\begin{tabular}{|l|c|c|}
\hline Signs & Frequency & Percentage \\
\hline Pallor & 57 & $73.07 \%$ \\
\hline Abdominal pump & 31 & $39.74 \%$ \\
\hline Cervical motion tenderness & 64 & 82.05 \\
\hline Adenexal mass & 61 & 78.20 \\
\hline Fullness in POD & 24 & 30.76 \\
\hline
\end{tabular}

Table 5: UPT interpretation in Ectopic Pregnancy

\begin{tabular}{|l|c|c|}
\hline UPT & Frequency & Percentage \\
\hline Positive & 75 & $96.15 \%$ \\
\hline Negative & 03 & $3.85 \%$ \\
\hline
\end{tabular}

Table 6 Risk factors in ectopic pregnancy

\begin{tabular}{|l|c|c|}
\hline Risk & Frequency & Percentage \\
\hline None & 43 & $55.12 \%$ \\
\hline Tubectomy & 05 & $6.41 \%$ \\
\hline PID & 13 & $16.66 \%$ \\
\hline IUCD & 07 & $8.97 \%$ \\
\hline D and C & 09 & $11.54 \%$ \\
\hline Previous Ectopic & 01 & $1.28 \%$ \\
\hline
\end{tabular}

Table 7 Different Sites of Ectopic Pregnancy

\begin{tabular}{|l|c|c|}
\hline Site of Ectopic & Frequency & Percentage \\
\hline Tubal & 73 & $93.58 \%$ \\
\hline Ovarian & 03 & $3.84 \%$ \\
\hline Corneal & 01 & $1.28 \%$ \\
\hline Cervical & 00 & $0 \%$ \\
\hline c/S scar & 01 & $1.28 \%$ \\
\hline
\end{tabular}

Table 8 Condition on Laprotomy

\begin{tabular}{|l|c|c|}
\hline Condition & Frequency & Percentage \\
\hline Ruptured & 62 & $79.48 \%$ \\
\hline Unruptured & 09 & $11.53 \%$ \\
\hline Tubal abortion & 07 & $8.97 \%$ \\
\hline $\begin{array}{l}\text { Secondary abdominal } \\
\text { pregnancy }\end{array}$ & 00 & $0 \%$ \\
\hline
\end{tabular}

\section{Discussion}

Ectopic pregnancy accounts for 3.5-7.1\% of maternal mortality in India ${ }^{13,14}$. The incidence of ectopic pregnancy was $0.44 \%$ in our study. This is in agreement with most studies from developing countries where incidence ranged from $0.56-1.5 \%$ $4-6,15,16$. It is a significant cause of mortality in the first trimester. Timely referral to a higher centre is imperative in order to reduce mortality and morbidity.

In this study majority of the patients $(70.51 \%)$ were in the age group of 20-30 years. Our results are in concordant with Panchal D et al ${ }^{17}(71.66 \%)$ and A Gaddagi et $\mathrm{al}^{18}(70.2 \%)$ while Porwal et $\mathrm{al}^{19}$ reported an incidence of $47.5 \%$ in age group of 21-25 years. In India most of the women marry at an early age and completes their family at an early age ${ }^{18}$. This age corresponds to the age of peak sexual activity and reproduction.

In this study we found that majority of women with ectopic pregnancy were multi gravida (71.8\%) while $28.2 \%$ were primi gravid. Multiparous woman was found to be more prone to ectopic pregnancy in Gaddagi et al ${ }^{18}$ i.e. $62.2 \%$; Shetty et al ${ }^{20}$ i.e. around $83.9 \%$ and Khaleeque et $\mathrm{al}^{5}$ study about $61 \%$. The higher incidence in multigravidate is probably due to previous miscarriages and infection resulting in tubal damage $^{21}$.

In this study we found that out of 78 cases of ectopic pregnancy all the patients i.e $100 \%$ have abdominal pain followed by $93.58 \%$ had amenorrhoea and $69.23 \%$ had bleeding problem. Our results are in consistent with M B Swami et $\mathrm{al}^{22}$ who also found all the patients having abdominal pain followed by amenorrhoea and bleeding problem. This shows that in ectopic pregnancy pain in abdomen, amenorrhea and bleeding is most frequent symptom. In study 
conducted by Rashmi Gaddagi et al ${ }^{18}$ found amenorrhea in $77.5 \%$, pain in abdomen in $89.2 \%$, bleeding $\mathrm{p} / \mathrm{v} 42.3 \%$.

In this study urinary pregnancy test was positive in $96.15 \%$ of the cases while $3.85 \%$ were negative. Our results are correlated with the study done by WM Fgeeh et $\mathrm{al}^{23}(96 \%) .10,16$ and Rashmi A Gaddagi, et $\mathrm{al}^{18}(97.3 \%)$ who also reported similar findings.(53-53-1). This shows that negative pregnancy test cannot rule out ectopic pregnancy.

In this study we found that there was no specific risk factor in 43 cases (55.12\%) while PID in 13 cases $(16.6 \%)$ followed by $\mathrm{D}$ and $\mathrm{C}$ in 9 cases $(11.54 \%)$, IUCD in 7 cases $(8.97 \%)$, tubectomy in 5 cases $(6.41 \%)$ and previous ectopic in one case (1.28\%). Similarly Meenakshi et $\mathrm{al}^{24}(38.71 \%)$ and Gaddagi et $\mathrm{al}^{18}$ found $37.83 \%$ had no apparent risk factors. Our findings are in line with the study conducted by V S Sudha et $\mathrm{al}^{21}$ who reported history of PID in $15.78 \%$ of the cases with ectopic pregnancy where as Bhavna et $\mathrm{al}^{25}$ reported $22.7 \%$ of the cases with ectopic pregnancy. Similarly Smita et $\mathrm{al}^{26}$ reported pelvic inflammatory disease was found to be strongest risk factor (35.29\%) and Yakasai, et $\mathrm{al}^{27}$ reported $(31.68 \%)$

In this study the commonest site for ectopic pregnancy was tubal $(93.58 \%)$ followed by ovarian $(3.84 \%)$ and cornual and C/S Scar both $(1.28 \%)$. Our results are in concordant with various authors who also reported the same findings. S Tahmina et $\mathrm{al}^{28}$ reported the fallopian tubes were the most common seat of ectopic pregnancy $(94.4 \%)$. Shetty $\mathrm{S}$ et $\mathrm{al}^{20}$ reported the commonest site of location of the ectopic pregnancy was in the ampulla of the fallopian tube seen in $45.2 \%$ cases. Similar findings were noted by Gaddagi $\mathrm{R}$ et $\mathrm{al}^{18}$ i.e. majority of the cases were ampulla pregnancies (69.7\%). Porwal S et $\mathrm{al}^{19}$ observed that ampullary portion of tubes (40\%) and isthmus (32.5\%) to be most common sites.

As medical management needs extremely close follow up and hospitalization, surgical management is still the method of choice in our country $^{29}$. Laparaoscopy and medical therapy have now emerged as the widely used therapeutic modalities with great succession in terms of reduced morbidity, shorter hospital stay and conservation of fertility ${ }^{30}$. In this study ruptured ectopic was present in $79.48 \%$ cases on laparotomy while $11.53 \%$ were unruptured ectopic cases and tubal abortion was found in $8.97 \%$ cases. Similar study conductd by Sabina et al who reported ruptured ectopic pregnancy in $62.3 \%$ cases, $24.5 \%$ had unruptured ectopic and tubal abortion in $13.9 \%$ cases. Similarly In Latchaw $\mathrm{G}$ et al study, tubal rupture was present in $59 \%$ cases and $41 \%$ had unruptured ectopic pregnancies. They concluded that the patients with a history of a previous ectopic pregnancy are significantly more likely to experience a tubal rupture $^{31}$.

\section{Conclusion}

Ectopic pregnancy is a leading cause in young reproductive woman. High degree of suspicion and early diagnosis is the key to successful management to reduce the morbidity and mortality associated with ectopic pregnancy.

\section{References}

1. Mahhoob U, Masher SH. Management of ectopic pregnancy, a two-year study. I Ayub Meb Coll Abbotthad. 2006; 18 (4):34-7.

2. Odendaal HJ, Schaetzing AE, Kruger TK. Textbook of Clinical Gynecology. 2nd Ed. Juta Academic publisher. Cape Town, South Africa;2001.

3. Cumminghum FG, Leveno, Bloon St, Hauth JC, Rouse DJ, Spong CY. Ectopic pregnancy; In Williams obstetrics, 23rd United States of America MC Graw Hills Publishing. 2010:238-54.

4. Singh S, Mahendra G, Vijayalakshmi S, Pukale RS. Clinical study of ectopic pregnancy in a rural setup: A two year survey. Natl J Med Res. 2014;4(1):37-9. 
5. Khaleeque F, Siddiqui RI, Jafarey SN. Ectopic pregnancies: A three year study. [2] J-Pak Med Assoc. 2001;51(7):240-2.

6. Udigwe GO, Umeononihu OS, Mbachu II. Ectopic pregnancy: a 5 year review of cases at nnamdiazikiwe university teaching hospital (NAUTH) Nnewi. Niger Med J. 2010;51(4):160

7. Walker JJ. Ectopic pregnancy. ClinObstet Gynecol. 2007;50:89-99

8. Berek JS, Berek DL. Berek and Novak's Gynecology. 15th edition. USA: Lippincott, Williams \& Wilkins, A Wolters Kluwer Business; 2012, p. 627.

9. Barnhart KT. Clinical practice. Ectopic pregnancy. N Engl J Med. 2009; 361:37987.

10. Sultana CJ, Easley K, Collins RL. Outcome of laparoscopic vs traditional surgeries for ectopic pregnancies. Fertil Steril 1992; 57:285.

11. Delacruz A, Cumming DC. The factors which determine the fertility after a conservative or radical surgical treatment for ectopic pregnancy. Fertil Steril 1997; 68:871.

12. Ory SJ, Villaneva AL, Sand PK. Conservative treatment of ectopic pregnancy with methotrexate. AM J, obstet, Gynecol. 1986;154:1299-306.

13. Shah P, Shah S, Kutty RV, Modi D. Changing epidemiology of maternal mortality in rural India: time to reset strategies for MDG-5. Trop Med Int Health. 2014;19(5):568-75.

14. Yadav K, Namdeo A, Bhargava M. A retrospective and prospective study [8] of maternal mortality in a rural tertiary care hospital of Central India. Indian $\mathbf{J}$ Community Health. 2013;25(1):16-21

15. Panti A, Tanko B, Yakubu A, Egondu S, Ikechukwu N, lukman O. Ectopic pregnancy at UsmanuDanfodiyo University Teaching Hospital Sokoto: A ten year review. Ann Niger Med. 2012;6(2):87

16. Igwegbe A, Eleje G, Okpala B. An appraisal of the management of ectopic pregnancy in a nigerian tertiary hospital. Ann Med Health Sci Res.2013;3(2):16670

17. Panchal D, Vasihanav G, Solanki K. Study of Management inpatient with Ectopic pregnancy. National journal of Integrated Research in Medicine. 2011;2(3):91-4

18. Gaddagi RA, Chandrashekbar AP. A Clinical Study of Ectopic pregnancy, Journal of clinical and Diagnostis Research. 2012;6:867-9

19. Gupta R, Porwal S, Swarnkar M, Sharma $\mathrm{N}$, Maheshwari P. Incidence, trends and risk factors for Ectopic Pregnancies in a tertiary care hospital of Rajasthan. J Pharm Biomed Sci. 2012;16(07):1-3

20. Shetty S, Shetty A. A clinical study of ectopic pregnancies in a tertiary care hospital of mangalore, India. Innov J Med Health Sci. 2014;4(1)305-9

21. Sudha VS, Delphine RT. A retrospective study on ectopic pregnancy: a two year study. Int J Reprod Contracept Obstet Gynecol 2016;5:4365-8

22. M. B. Swami, Parul Sharma, Manvi Tyagi, Rinku Kuswaha, Juhee Harit. "Clinical Study of Ectopic Pregnancy". Journal of Evolution of Medical and Dental Sciences 2015;4(86):15057-62

23. Fageeh WM. Diagnosis and Management of Ecotopicpregancyin king Abdul Aziz University Hosptial, a Four year Experience, Medical science. 2008:15(2).

24. Chate MT, Chate B, Chate. Clinical study of ectopic pregnancy. Int $\mathrm{J}$ Reprod Contracept Obstet Gynecol 2017;6:34983501.

25. Gupta BK, Pathania BK, Jindal M, Vohra R, Ahmed M. Risk Factors For Ectopic Pregnancy; A case Control study in 
Tertiary care Centre, Journal of Dental and Medical Sciences. 2014;13(3):23-7.

26. Smita Kumari, Dipali Prasad, Archana Sinha, Sadia Parween. Retrospective study of ectopic pregnancy in tertiary care centre. IAIM, 2018;5(1):95-9

27. Yakasai IA, Abdullahi J, Abubakar IS. Management of ectopic pregnancy in Aminu Kano teaching hospital Kano Nigeria: Glob Adv Res J Med Med Sci., 2012;1:181-5

28. S Tahmina, Mary Daniel, Preethy Solomon. Clinical Analysis of Ectopic Pregnancies in a Tertiary Care Centre in Southern India: A Six-Year Retrospective Study. Journal of Clinical and Diagnostic Research. 2016;10(10):13-6

29. Chatterjee S, Dey S, Chowdhury RG, Ganguli D. Ectopic pregnancy in previously infertile women pregnancy in previously outcome after laparaoscoptic Management Al amen J Med Sck. 2009;2(1):67-72.

30. Jurkovie D, Ectopic pregnancy, IN: Edmonds DK, Editor, Dew Hurst textbook of obstetrics and Gynecology 7ed, USA: Blackwell Publishers. 2007.

31. Latchaw G, Takacs P, Gaitan L, Geren S, Burzawa J. Risk factors associated with the rupture of tubal ectopic pregnancy. GynecolObstet Invest. 2005;60(3):177-80. 